$\mathrm{p}<0.0001$. At higher levels of $\mathrm{CO}_{2}$ emissions there was no association with life expectancy. Among 30 countries with high life expectancy ( $>75$ years) and relatively low $\mathrm{CO}_{2} \mathrm{pc}$ emissions $(<10 \mathrm{t}$ ) with a population $>0.5 \mathrm{M}$ there was a modest association overall between $\mathrm{CO}_{2}$ emissions and life expectancy (rank correlation $0.51, \mathrm{p}=0.004$ ). Within this group, life expectancy ranged between 75.5 (Argentina, annual emissions $4.6 \mathrm{t}$ ) and 82.5 years (Switzerland, $5.1 \mathrm{t}$ ). Using the 2008 World Bank income classification, per capita emissions were associated with life expectancy among low and low middle income countries, but not in high middle or high income countries.

Conclusions Life expectancy, a surrogate indicator of population health, is unrelated to energy consumption above a low level. It appears, looking to the future, that the environmental sustainability and global health development agendas are compatible in practice.

\section{SP4-33 RISK FACTORS FOR LOW BIRTH WEIGHT IN THE MUNICIPALITIES OF JUAZEIRO AND PETROLINA (BRAZIL): A CASE-CONTROL STUDY}

doi:10.1136/jech.2011.142976p.27

${ }^{1} S$ S Cruz, ${ }^{1}{ }^{1} \mathrm{~L}$ Souza, ${ }^{1}$ A C G Figueiredo, ${ }^{1} \mathrm{R}$ S Davoglio, ${ }^{2}$ I S Gomes-Filho, ${ }^{2} \mathrm{~J}$ S Passos, ${ }^{1} \mathrm{G} M$ Pinto Coelho, ${ }^{2} \mathrm{~J} \mathrm{M}$ F Coelho. ${ }^{1}$ Univsidade Federal do Vale do São Francisco, Petrolina, Brazil; ${ }^{2}$ Universidade Etadual de Feira de Santana, Feira de Santana, Brazil

The aim of this study was to evaluate the association between maternal characteristics and low birth weight (LBW). An exploratory case-control investigation was conducted in two hospital that provide attendance through SUS in neighbouring municipalities: Petrolina (Pernambuco) and Juazeiro (Bahia), Brazil. The sample consisted of 588 puerperae, of whom 136 were in the case group (women with low-weight children) and 452 in the control group (mothers of normal-weight children). In the data analysis procedures, the distribution of the variables was evaluated using the $\chi^{2}$ test at the significance level of $5 \%$. This study was approved by the Research Ethics Committee of UEFS (CAAE: 0151.0.0590.000-08). The results demonstrated that LBW was associated with the mother's occupation during pregnancy $(p=0.04)$, father's schooling level $(p=0.01)$, mother's race/colour $(p=0.00)$, municipality of origin $(p=0.01)$, mother's age $(p=0.00)$, number of prenatal consultations $(p=0.00)$, presence of pregnancy card at time of delivery $(p=0.00)$, number of consultations with a medical professional $(p=0.04)$, number of pregnancies $(p=0.01)$ and gestational age $(p=0.00)$. However, there were no statistically significant associations with the other variables. The findings reaffirm that having quality prenatal care is of utmost importance, with greater efforts made towards identifying factors that are associated with LBW, with a view to reducing the occurrence of this undesirable gestational outcome.

\section{SP4-34 FACTORS ASSOCIATED WITH QUALIFIED MEDICAL CARE FOR SICK NEONATES AMONG URBAN POOR IN LUCKNOW, NORTHERN INDIA}

doi:10.1136/jech.2011.142976p.28

\begin{abstract}
${ }^{1,2} \mathrm{~N}$ M Srivastava, ${ }^{2} \mathrm{~S}$ Awasthi. 'Johns Hopkins University-King George's Medical University Collaborative Research Projects, Lucknow, India; ${ }^{2}$ Department of Paediatrics, King George's Medical University, Lucknow, India
\end{abstract}

Introduction This study assessed factors associated with qualified medical care-seeking (OMC) for sick neonates among urban poor. Methods The study was conducted at an urban Reproductive and Child Health (RCH) center and free facility of the District hospital. Neonates were enrolled within $48 \mathrm{~h}$ of birth and were followed-up once at 6 weeks \pm 15 days at the outpatients' clinic of the respective hospitals or at home.

Results 510 neonates were enrolled and 481 (94.4\%) were followedup. Parents of $50.3 \%(242 / 481)$ neonates reported at least one sign of illness and $80.1 \%(196 / 242)$ of these went to at least one type of medical provider, while $50.8 \%(123 / 242)$ went to at least one qualified medical provider. $6.6 \%(16 / 242)$ went to traditional/spiritual healers. Mothers who delivered at RCH center $(p<0.001)$, those with no schooling $(p=0.02)$, those with parity $>4(p=0.007)$, those who made $<3$ ANC visits $(p=0.002)$ and families with uneducated fathers $(p=0.02)$ and income $<2500$ Indian Rupees $(p<0.001)$ were less likely to seek $\mathrm{OMC}$ that their counterparts. In Multiple Logistic Regression Model, delivery at RCH center, family income $<2500$ INR and fewer $(<3)$ ANC visits significantly predicted no QMC for sick neonates.

Conclusion Since more than half of the neonates have morbidity, $\mathrm{OMC}$ for sick newborns should be promoted in urban Lucknow. Interventions promoting $\mathrm{OMC}$ for sick newborns should especially focus on uneducated mothers \& fathers, mothers who make fewer ANC visits, mothers with high parity, those belonging to lower income groups and those delivering at the lower tier public health facilities.

\section{SP4-35 "SENSE OF INJUSTICE" A MECHANISM TO EXPLAIN SOCIAL INEQUALITIES IN HEALTH}

doi:10.1136/jech.2011.142976p.29

A Kaddour.* INSERM Equipe Determinants Sociaus et professionels de la sante, Villejuif, France

Background There is an increasing interest in the literature to examine plausible mechanisms explaining social inequalities in health above and beyond income. We propose "sense of injustice", coined by Cahn, a sociologist, in 1950, and denoting a cognitive process rather than a psychological individual reaction to unjust social and economic structures in society while reckoning that people regard themselves in relation to each other, as a community. Methods The data used are from the Ras Beirut well-being survey designed for this purpose by a cross-disciplinary research team and conducted in 2009 in a socially and economically diverse neighbourhood of Beirut, Lebanon. To measure sense of injustice, a 17item instrument with five-point Likert scale responses was developed trough an engaged reiterative qualitative and quantitative process. A random sample proportional to cluster size of 1200 households sample was drawn using spatial sampling techniques to maximise contextual variability. A proxy was interviewed on the household social, economic and demographic variables and one randomly chosen adult member ( $>21$ years) answered the individual questionnaire. The vast majority of interviews were conducted in Arabic and the response rate was $56.25 \%$.

Analysis Exploratory factor analysis was used to identify the common factors among the measured variables for sense of injustice. Using ecosocial theory of disease distribution, specifically the notion of embodiment, the association between sense of injustice and selfrated health was examined adjusting for relevant exposures.

Implications Proposed interventions to reduce health inequalities should address the structural issues of economic inequality and power imbalance.

\section{SP4-36 DESCRIPTION OF EPIDEMIOLOGIC SITUATION OF HIV/AIDS IN ECUADOR, SOUTH AMERICA 2000-2009}

doi:10.1136/jech.2011.142976p.30

C V Erazo. * Ministério de Salud Pública del Ecuador, Programa Nacional de Prevencion y Tratamiento de VIH/SIDA e ITS, Quito, Pichincha, Ecuador

Introduction HIV/AIDS in Ecuador is a concentrated epidemic $(<1 \%$ in the general population and $>5 \%$ in high risk groups). The aim of 